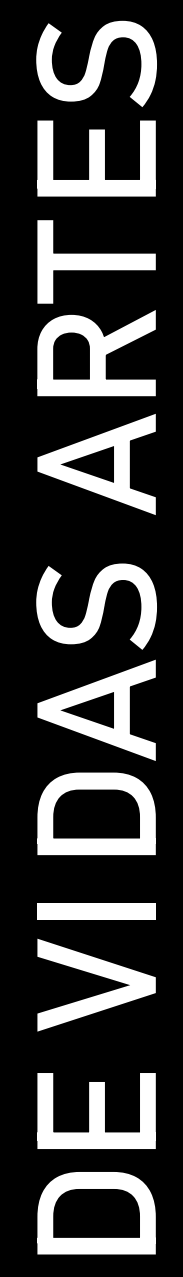

PAULA GUERRA E LÍGIA DABUL (EDS.) 


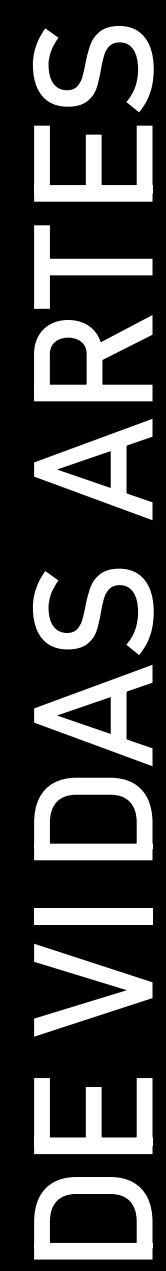

\section{PAULA GUERRA E LÍGIA DABUL (EDS.)}

Design por Irandina Afonso

Ilustração da Capa por Lua Celina

Publicado em Setembro 2019

Universidade do Porto. Faculdade de Letras

[University of Porto. Faculty of Arts and Humanities]

Porto, Portugal

ISBN 978-989-8969-18-7

Suporte: Eletrónico - Formato: PDF / PDF/A 


\title{
1.5. Coletivos de arte: notas sobre memória, política e autoria
}

\section{I.5. Art Collectives: notes on memory, politics and}

\section{authorship}

\section{Ana Carolina Freire Accorsi Miranda}

\section{Resumo}

Este capítulo aborda questões que permeiam a historiografia dos coletivos de arte no Brasil de modo a mostrar as possíveis contaminações desses grupos em outras esferas do mundo da arte, tais como a curadoria e a gestão de museus. Para isso, realiza-se uma retrospectiva das principais fases que marcaram esse percurso, abordando mitos de origem e momentos-chave pertencentes ao processo de consagração dos coletivos ao longo das últimas décadas. Em seguida, destaca-se a relação entre as transformações urbanas recentes e o crescimento desses grupos. Depois, discute-se a influência do contexto político nas supracitadas contaminações. Por fim, analisa-se de modo mais amplo a autoria colaborativa na sociedade contemporânea.

Palavras-chave: coletivos de arte, memória, musealização, política, autoria.

\begin{abstract}
This chapter deals with issues that permeate the historiography of art collectives in Brazil, seeking to show the possible contaminations of these groups in other spheres of the art world, such as curatorship and museum management. Initially, it seeks to carry out a retrospective of the main phases that marked this period, including the myths of origin and key moments of the gradual process of consecration of collectives in the last decades. Next, the text highlights the relationship between recent urban changes and the growth of these groups. Then, the political context and its contamination in this area of art is discussed and finally an analysis is presented on the collaborative authorship in contemporary society.
\end{abstract}

Key words: collectives of art, memory, musealization, politics, authorship.

\section{Introdução: a trajetória dos coletivos e suas contaminações colaborativas}

Ao refletir sobre a arte contemporânea em sua fase mais recente, o artista Dan Grahan afirma: "Todos os artistas são iguais. Eles sonham em fazer algo mais social, mais colaborativo e mais real que a arte" (Grahan In Bishop, 2012: 1). Hoje é possível adicionar curadores e instituições a esse rol de sonhadores. Pois, mesmo sem que esses grupos se autoproclamem "coletivos", características que antes pareciam restritas a eles vêm sendo também encontradas, valorizadas e enfatizadas nos discursos produzidos por 
críticos, curadores, instituições e artistas individuais. De fato, observa-se um alargamento da influência dos coletivos no campo artístico (Madeira, 2016; Resende \& Scovino, 2010; Miranda, 2016). Não só artistas individuais estão usando cada vez mais estratégias autorais coletivas, como também as curadorias estão se descentralizando. Seguindo essa tendência, as gestões dos museus têm procurado integrar-se mais ao público por meio do discurso do 'construir juntos' novos paradigmas artísticos. Assim, este capítulo aborda tanto as fases específicas que se destacaram no surgimento e na trajetória dos coletivos quanto suas possíveis contaminações em outras esferas do mundo da arte ${ }^{70}$.

\section{As efervescências coletivas}

Já que o movimento dos coletivos de arte contemporânea dos anos 2000 tem agora quase duas décadas de história, é possível, hoje, destacar algumas fases de maior efervescência dentro deste percurso. A adoção do prenome "coletivo começa a surgir a partir do final dos anos 1990 no Brasil através de um duplo processo entre a demanda de curadores institucionais e a iniciativa prática dos artistas. Em seguida, veio uma fase de expansão e consagração nos anos 2010, acompanhando o crescimento dos eventos e do mercado de arte contemporânea nacional deste período (Fialho, 2017).

O surgimento desses grupos vem acompanhado de 'mitos de origens', redes de amizades que aparecem como momentos-chave da reconfiguração desse campo, ocorrida no Rio de Janeiro e em São Paulo. Neste segundo estado, observa-se uma aliança entre diversos coletivos de arte e movimentos sociais envolvidos na luta por moradia, todos girando em torno da ocupação Prestes Maia, acontecida entre 2003 e 2007 (Mussi, 2014). Também em São Paulo, nos anos 2000, os monitores da espetacular Mostra do Redescobrimento Brasil +500 pedem demissão e formam um coletivo precursor chamado MICO (Mussi, 2014). Já no Rio de Janeiro, são recorrentemente citados os seguintes grupos: Rés do chão, Zona Franca (regido pelos integrantes do Atrocidades Maravilhosas). E também a rede de amizades em torno da escola de artes da Escola de Belas Artes da Universidade Federal do Rio de Janeiro, no começo dos anos 2000 (Pires,

\footnotetext{
${ }^{70}$ Este capitulo resulta do desenvolvimento do projeto de doutoramento da autora intitulado "Diálogos entre autoria e política: a colaboração na arte carioca pós junho de 2013", desenvolvido no quadro do Programa de Pós-Graduação em Sociologia e Antropologia da Universidade Federal do Rio de Janeiro com realização de Doutorado Sanduíche na Humboldt-Universität Zu Berlin na Alemanha. O trabalho é orientado cientificamente pelas Professoras Doutoras Angela Lammert e Glaucia Villas Bôas.
} 
2007; Rezende \& Scovino, 2010; Fernandes, 2018). Em paralelo, fora do eixo Rio-São Paulo, pode-se destacar o grupo Empreza de Goiás, o GIA da Bahia e Coletivo Poro de Belo Horizonte como pioneiros deste tipo de arte no Brasil.

Também tidas como marcos iniciais, por serem de grande porte e terem abordado o tema colaborativista com a mesma tônica dos coletivos, destacam-se duas grandes exposições: Panorama da Arte Brasileira $2001 \mathrm{e}$ a 27. a Bienal de Arte de São Paulo. A primeira reuniu uma parte dos artistas ligados a coletivos cariocas, como o Atrocidades Maravilhosas. A segunda, intitulada Como viver junto, trouxe diversos coletivos da Argentina e abriu um espaço para o debate acerca desse tipo de arte em grandes eventos, mesmo tendo catalogado apenas um coletivo brasileiro de São Paulo em sua lista de artistas.

Também o Rumos teve papel importante neste processo, tendo realizado no início dos anos 2000 suas primeiras edições desenvolvidas por curadores consagrados como Fernando Cocchiarale e Lisette Lagnado, esta ainda a curadora da $27^{\text {a }}$ Bienal de São Paulo. O Rumos aparece como o primeiro projeto a mapear a jovem arte contemporânea brasileira, destacando artistas ligados a coletivos, além dos próprios grupos. Seu primeiro curador, Fernando Cocchiarale, relata que a grande descoberta desse mapeamento havia sido a proeminente arte política e colaborativa sendo produzida pelo Brasil naquele momento (Cocchiarale In Motta, 2018). Nota-se, assim, que esses eventos foram imprescindíveis para a institucionalização, incorporação e legitimação dos coletivos no circuito consagrado de arte.

Gustavo Motta (2018) afirma que o processo gradual de legitimação e institucionalização desses grupos não teria sido apenas em resposta à demanda dos artistas, mas também uma premissa vinda 'de cima', segundo suas próprias palavras. Para este autor, haveria ocorrido efetivamente um projeto de artificação de iniciativas colaborativistas e socialmente engajadas em consonância com o momento político de inovação-conservação na política nacional. Em outra publicação (Miranda, 2016), discorro sobre a artificação dos coletivos de arte nos anos 2000 e também uma espécie de projeto de institucionalização predominante na história dos coletivos neste período. Nesta ocasião, desenvolvo como curadores em alguns casos estariam impondo o nome coletivo aos grupos da mostra Panorama da Arte Brasileira 2001 ao enquadrarem teórica e discursivamente uma ação das ruas dentro de uma exposição de arte. Ainda pensando esta artificação como um projeto, 
para Motta (2018), a 27ª Bienal de São Paulo se abre para os coletivos por uma questão prática de corte de gastos, o que acaba por impulsionar uma reconfiguração curatorial, eliminando as divisões entre países e trazendo uma demanda institucional por novidade.

Fica ainda mais claro que a 27. ${ }^{\text {a }}$ Bienal de São Paulo em 2006 se tornou um marco da arte coletivista quando observa-se a sua divisão em três setores, os quais por sua vez ecoam os três aspectos que continuam agitando os discursos de coletivos até hoje: 1) questões de moradia e memória; 2) questões sociais e políticas; 3 ) colaboração e diluição de autoria como 'nova utopia'. Cada andar da Bienal de São Paulo seguia este recorte conceitual triplo, como demonstra a fala da curadora Lisette Lagnado:

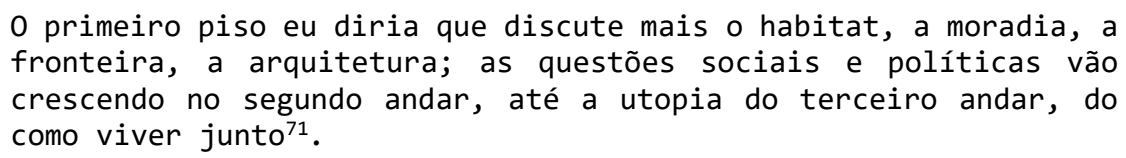

Partindo do enunciado da curadora e em consonância com as pesquisas realizadas para este artigo, percebe-se que é impossível pensar o colaborativismo na arte brasileira dos últimos anos sem pensar nas suas relações com o espaço urbano, com questões políticas e com a dimensão utópica da autoria artística colaborativista. Com efeito, a movimentação da arte contemporânea brasileira se dá em direção à coletividade como forma legítima e valorizada de autoria. Essa movimentação pode ser observada tanto na significativa presença de obras colaborativas com temática sóciopolíticas quanto no próprio projeto de gestão empreendido pelas instituições artísticas. No entanto, pode-se perguntar acerca das circunstâncias que possibilitaram esse movimento coletivo que assolou os artistas e o projeto de artificação institucional. De que forma discursos e práticas se engendram e produzem a vida social nesse campo? Essas questões sociológicas são abordadas ao longo ao longo do capítulo em seguida.

\section{Coletivos, musealização e memória}

Como visto, os espaços urbanos são tanto alvo de reflexão quanto local de produção dos coletivos. Portanto, analisar as transformações ocorridas nas cidades e nas políticas dos museus na virada de século XXI pode ajudar a

\footnotetext{
${ }^{71}$ Entrevista de Lisette Lagnado à Redação UOL. "Para curadora, Bienal deve formar um espírito do tempo". setembro 
entender a presença desses temas nas produções dos coletivos, uma vez que, como afirmou o sociólogo Georg Simmel, analisar a arte de um tempo é analisar um microcosmo de sua sociedade (Waizbort, 2000).

O início do século XXI foi palco de profundas mudanças urbanas e políticas no Brasil e no mundo. Houve uma reconfiguração das cidades em nome de um modelo global, tal qual discutido pela filósofa Otília Arantes (2014) e pelo geógrafo David Harvey (2013). Nessa esteira nascem os estatutos das cidades e também a conhecida expressão 'direito à cidade'. A pauta da luta por moradia cresce entre os movimentos sociais no Brasil, principalmente grupos anarquistas e antiglobalização, ao passo que se fragilizaram os movimentos sindicais e partidários (Motta, 2018).

A pauta da cidade ecoou fortemente nos protestos de junho de 2013, nos da Copa do Mundo de 2014 e das Olimpíadas de 2016, momentos hoje tornados marcos históricos. Foram épocas de grandes reformas nas cidades, às quais os inúmeros protestos que ocuparam e ressignificaram os espaços urbanos tentavam resistir. Os megaeventos esportivos trouxeram, dentre outras transformações, a grande reforma da zona portuária do Rio de Janeiro promovida pela gestão de Eduardo Paes, reforma que veio acompanhada da construção de dois museus monumentais: o Museu de Arte do Rio (MAR) e o Museu do Amanhã. A exemplo do surgimento desses museus em tal contexto político, portanto, pode-se dizer que a transformação do espaço urbano contaminou a criação dos artistas atuantes nas cidades, principalmente em trabalhos desenvolvidos em colaboração e nas exposições curadas em museus do Rio e de São Paulo.

O termo 'gentrificação' estava estampado tanto nos lambes espalhados pelas ruas do coletivo Bijari, em São Paulo nos anos 2000, quanto na bandeira das performances do coletivo carioca Seus Putos em frente ao Museu do Amanhã, nos anos 2010. Imagens dessas ações foram depois incorporadas em exposições no MAR e no Centro Municipal de Arte Hélio Oiticica (CMAHO). Com isso, percebe-se que a institucionalização de ações críticas acerca do direito à cidade parecem se dar de forma cada vez mais imediata. Vê-se também que o termo gentrificação tem abandonado os muros da academia e tomado as ruas por meio de artistas e ativistas, o que leva a crer que a desconstrução e reconstrução da cidade do Rio de Janeiro incluindo a inauguração dos novos museus - tem reverberado na criação artística local. E isso simultaneamente ao processo de 'musealização das 
cidades' próprio da virada de século, e que Otília Arantes chamou de virada cultural dos projetos de cidade (Arantes, 2014).

Como lembra Mario Chagas (2003), a construção da instituição museu se dá sempre atrelada a projetos de mudanças sociais. Da mesma maneira que a ocupação Prestes Maia marcou a história dos coletivos ao atrelar-se à luta por moradia em São Paulo, a inauguração do MAR também foi pautada como um acontecimento que reflete a memória coletiva do Rio de Janeiro. Contudo, se no caso do Rio esse reflexo entre musealização e criação artística é evidente, já em São Paulo as mudanças urbanas podem não ter tido um marco monumental estrutural em formato de museu. De todo modo, para além da crescente especulação imobiliária, o aquecimento das bienais de arte e a Mostra do Redescobrimento +500 podem ser consideradas construções simbólicas que alteraram as noções de memória e desencadearam respostas dos coletivos locais e manifestações. Essas provocações à memória e à musealização das cidades contribuiu para que a arte política contaminasse as curadorias dos museus neste período por meio de um processo de retroalimentação entre discursos institucionais e práticas sociais.

Ainda segundo Chagas (2003), essas instituições são lugares de memória e de esquecimento concomitantes. Ou seja, a musealização das cidades figura não só como consequência, mas também como causa da configuração do ânimo dos artistas, num processo de feedback. Com isso concorda a pensadora da memória cultural Aleida Assman (2016), ao afirmar que os produtores de arte acabam se destacando justamente num momento histórico em que a memória oral vem se perdendo vertiginosamente. Para ela, os artistas são aqueles que vem pensando e construindo a memória cultural após os anos 70 , quando a memória oral começa a perder força. Neste período, consequentemente também os museus começam a se reconfigurar, surgem os museus-espetáculo, proliferam-se os centros culturais (Sant'anna, 2012), todos apoiados na amplificação da democratização dessas instituições. Ao mesmo tempo, pautadas numa democratização alinhada às minorias étnicas e raciais, aparecem os museus comunitários e os ecomuseus, movimento este que Mario Chagas chama da "democratização da tecnologia museu" (Chagas, 2005).

Essa ambiguidade entre memória e esquecimento parece acompanhar sempre as relações entre museu, memória e cidade. Segundo 
Aleida Assman (2016), refletir sobre a memória é pensar a amnésia, da mesma maneira que pensar a cidade é pensar destruição e criação (Harvey, 2013). Na mesma linha, para Georg Simmel a cidade é um espaço que nos une ao mesmo tempo que nos separa (Simmel In Waizbort, 2000). Com essas caracterizações dialógicas, tenta-se aqui entender a relação entre arte e cidade, tão recorrente na arte colaborativa e socialmente engajada atual, sem ignorar suas ambiguidades.

Também é interessante destacar que as transformações da memória cultural descritas por Assman (2016) abordam o crescente papel da recordação na vida pública, de onde emerge um novo significado para a noção de 'memória' na cultura contemporânea. A memória torna-se então parte da discussão pública, ao mesmo tempo que elemento essencial para a criação identitária individual e coletiva, palco tanto para conflitos quanto para identificações. Nesse sentido, Assman chama atenção para o papel da arte pós década de 1970, quando as práticas artísticas começam a se ocupar cada vez mais da memória num momento em que a sociedade parece ir em direção ao seu apagamento ou esquecimento. Tematizando essa crise, a arte encontra novas formas para expressar a dinâmica da recordação e do esquecimento culturais. Talvez por isso a recorrência da palavra gentrificação tenha saído da academia para as artes. Pois a gentrificação destrói locais históricos de ativação da memória cultural, abrindo assim espaço para que a arte se torne espelho do esquecimento e do recalque do inconsciente coletivo, bem como seu instrumento de medição. Mas talvez não se possa falar somente em perda, e sim também em transformações: espelho e régua, a arte reflete e mede a dinâmica da recordação e do esquecimento culturais (Assman, 2016), como fica claro nos trabalhos dos coletivos atentos às transformações no espaço urbano e seus subsequentes desdobramentos sociais.

De modo mais amplo, Assman aponta ainda que a arte das sociedades ocidentais se desenvolveu nesse mesmo sentido de memória e esquecimento a partir da década de 1970, tendo se tornado dominante na década de 1980. Contudo, ela não acredita que tenhamos alcançado o ponto máximo desta "onda de memória" na arte, e observa que essa fascinação continua a se desenvolver. Essa continuação teria a ver com um novo interesse político no poder subversivo da lembrança, cujo objetivo seria refrear o avanço totalitário do esquecimento. A partir da Segunda Guerra e, depois, do temor diante da 
guerra atômica, essa ocupação com a memória teria a ver com o desenvolvimento de uma consciência entusiasmada com a força da perda, com o potencial autodestrutivo das sociedades modernas e, por fim, com a situação fundamentalmente precária da memória na era da cultura de massa e suas técnicas eletrônicas de armazenamento e circulação. "É como se a memória, sem ter mais forma cultural nem função social, tivesse se refugiado na arte" (Assman, 2016: 385).

É impossível ignorar as semelhanças entre essa afirmação e o ocorrido com o Coletivo És uma Maluca no primeiro mês de 2019, no Rio de Janeiro. O coletivo realizou uma performance que reapresentava ao público uma memória social apagada (já que no Brasil não tivemos um museu sobre a ditadura): a prática de torturadores da ditadura militar brasileira de introduzir baratas nas genitálias das presas políticas. O apagamento, inclusive, se deu duas vezes, pois a performance foi censurada e não pode ser realizada nem mesmo dentro da instituição que inicialmente a aprovou. O coletivo então a deslocou para o lado de fora da Casa França Brasil, no espaço público.

As produções artísticas ensaiam uma saída à rua, e a rua invade discursivamente a arte. É também emblemático o caso da exposição Zona de Poesia Árida, de janeiro a julho de 2015 no térreo do MAR, uma mostra sobre os trabalhos dos coletivos artísticos e ativistas de São Paulo, onde muito se discutiu sobre a validade da crítica à gentrificação dessa cidade aventada por uma instituição ela própria muitas vezes criticada por promover a gentrificação, - a reforma do Porto Maravilha - na cidade do Rio de Janeiro. $E$ assim o MAR foi se construindo através do reconhecimento institucional de certos grupos ao mesmo tempo que causava repúdio a outros. Por isso, podese concluir por ora que esta breve história dos coletivos parece tangenciar sempre as ambiguidades, os híbridos e os não-lugares, intercambiando o 'dentro' e o 'fora' da arte estabelecida e sempre discutindo a crítica institucional - tema que parece perseguir a história das vanguardas das artes visuais.

\section{Aproximações entre arte e política}

O momento histórico-político em que surgem os coletivos de arte no Brasil foi marcado pela crise do segundo governo de Fernando Henrique Cardoso (Motta, 2018). Este período pode ser resumido grosso modo como um momento em que os movimentos sociais sindicalistas passavam por um 
arrefecimento, enquanto cresciam os grupos anarquistas de jovens ligados à cultura punk (Guerra, 2014). As lutas por moradia e a reivindicação pelo direito à cidade passam a ser a pauta da vez, e as questões urbanas começam a entrar em voga devido ao processo de reconfiguração das cidades já descrito. Com o avanço da Internet, os coletivos começam a utilizar as mídias digitais para se articular, produzir arte e 'contrainformação'. Já no governo Lula, o então Ministro da Cultura Gilberto Gil legitima, em discurso público, a Internet como cultura digital, mais que simples tecnologia, promovendo assim uma aproximação entre o governo e grupos independentes de arte e mídia (Mussi, 2014). Este momento é também marcado pela quarta edição do festival internacional Mídia Tática - Next Five Minutes 4 realizado pela primeira vez em São Paulo em 2003. Este foi um dos marcos da história dos coletivos de arte por ter sido um importante momento de articulação entre ativistas e artistas do Brasil e do mundo nos anos 2000 (Mussi, 2014).

Aquece-se assim a politização da arte e começa-se a desenhar os primeiros traços da arte política brasileira nos moldes do século XXI. A respeito desta guinada à politização no mundo da arte recente, discuti juntamente com Guilherme Marcondes e Sabrina Parracho Sant'Anna (2017) os efeitos mais amplos dessa questão, tais como a abertura de novos modelos de instituições pela cidade, as mudanças no papel do curador e as transformações das políticas do Ministério da Cultura ao longo dos anos 2000 que acompanharam essa mudança na arte brasileira. Uma vez destacadas essas mudanças, no presente capítulo busco evidenciar especificamente 0 caráter colaborativo dessa politização e suas relações com questões de urbanidade, de autoria e de utopia.

É interessante notar que a noção de política presente na arte de hoje parece passar perto do ativismo político combativo direto (em oposição ao ativismo 'conceitual' ou indireto da arte política da década de 1960). Hoje, os próprios artistas fazem parte de movimentos sociais, ou então formam parcerias com os ativistas para criarem suas obras, como pode ser observado na exposição “Arte, Democracia e Utopia: Quem não luta está morto!” em cartaz no MAR em 2018. Em outro caso, em 2017, um artista berlinense exclamou em entrevista para esta pesquisa uma frase que pode também ilustrar o momento atual: "Os artistas estão tratando de política de maneira 'pornográfica!'”, aludindo à falta de uma linguagem artística conceitual e à predominância de uma abordagem com cunho demasiadamente jornalístico 
e documental dos fatos políticos em trabalhos de arte encontrados em Bienais e Documentas.

A relação dos artistas com o ativismo politico no Brasil se acentua após junho de 2013, como se percebe a partir das entrevistas com artistas para catálogos de mostras de arte, onde são frequentes as referências às manifestações de junho, que aparecem como um divisor de águas não só na história política mas também, e consequentemente, na história da arte. Notase isso de forma mais nítida na exposição Junho de 2013: 5 anos depois, com curadoria geral de Daniele Machado e Gabriela Lúcio, hospedada no Centro Municipal de Arte Hélio Oiticica no Rio de Janeiro, em 2018.

De fato, as jornadas de junho podem ser caracterizadas como deflagradoras de criações artísticas coletivas de cunho ativista. Os protestos influenciaram boa parte das exposições que tinham como propósito declarado a transformação social, exposições aliás cada vez mais estabelecidas e prestigiadas, ao mesmo tempo que saíram das ruas para dentro dos museus. Também a partir de junho de 2013 o protagonismo dos coletivos e das manifestações colaborativas ocasiona um relevante aumento da institucionalização da arte colaborativa, como provam diversos estudos que abordam exposições cujos temas aproximam processos artísticos ao ativismo político em importantes eventos no Brasil e no mundo. Esses foram os casos da última exposição de Lula Wanderley no Centro Municipal de Arte Hélio Oiticica no Rio de Janeiro, em 2017, e das obras do Coletivo Guerrilla Girls, que já expôs em diversos países, e que vem denunciando, por meio de cartazes explicativos e estatísticos, a grande desigualdade entre o número de obras masculinas e femininas presentes em museus, além dos seus conteúdos machistas.

Com isso tudo, tento aventar a hipótese de que diversos fatores influenciaram o boom do coletivismo para muito além do aquecimento dos ativismos vivido no Brasil nos últimos anos. Acompanhamos um cenário político em que a política se estetizou e a arte se politizou. Inclusive na política eleitoral. $\mathrm{Na}$ nossa era de proliferação de imagens, mesmo as recentes eleições brasileiras sofreram guinadas à direita, num processo pautado por desconfianças de associações entre os políticos eleitos e companhias 
especialistas em manipular a discussão política ${ }^{72}$ - também por meio da estética. Tudo aponta para a diluição das fronteiras entre estética e política no cenário contemporâneo - não só em referência à colaboração coletivista, que ativa a crítica ao modelo social excludente a partir da esfera da arte, como ao retorno ao conservadorismo a partir da estética.

\section{Autoria colaborativa: da arte à sociedade ocidental contemporânea}

Para além das mudanças nas cidades e da aproximação entre arte e política no Brasil, quais fatores possibilitaram o crescimento do coletivismo nas artes contemporâneas? Esta pergunta parece ainda mais pertinente quando se pensa que o coletivismo nasce numa modernidade tão baseada na ideologia do 'indivíduo' que, tendo se tornado individualista ao extremo, alguns autores a caracterizam como a época da 'exploração de si', na qual o próprio indivíduo explora a si mesmo numa eterna busca pelo melhor desempenho pessoal.

De fato, o individualismo exacerbado da sociedade ocidental que emergiu das dicotomias da Guerra Fria classificou toda forma de coletivismo como originando-se de um comunismo cerceador da liberdade individual. Mas parece que um novo tipo de coletivismo, alinhado aos ideais ocidentais, também pode ter surgido no momento posterior à queda do muro de Berlin: 0 "coletivismo capitalista", que teria ressignificado o coletivismo contracultural modernista (Stimson \& Sholette, 2007). "Há um espectro assombrando a globalização do capitalismo, o espectro de um novo coletivismo" (Stimson \& Sholette, 2007: 1). É no interior desse espectro que o mundo da arte sinaliza o acolhimento dos coletivos, e mais: os coletivos se institucionalizam e as instituições se coletivizam.

Segundo a hipótese deste estudo, e para recapitular, esta coletivização no mundo da arte vem ocorrendo principalmente por meio de uma tríplice mudança: 1) a produção artística busca a colaboração desenfreada; 2) 0 conceito de museu se expande em ideais descentralizadores; 3) e as curadorias se tornam autorais e coletivistas. Mais ainda: essa coletivização, hoje, beberia na fonte do espectro coletivistacapitalista, consequência neoliberal do conflito global entre capitalismo e

\footnotetext{
72 Mais detalhes sobre essas especulações na Carta Capital de outubro de 2018: Disponível em: https://www.cartacapital.com.br/politica/as-pistas-do-metodo-201ccambridge-analytica201d-na-

campanha-de-bolsonaro/ Acesso em: 10 de fevereiro de 2018.
} 
socialismo na guerra fria, que por sua vez deu peso definido para a ideia de 'cultura' (Stimson \& Sholette, 2007).

Da mesma forma que Gustavo Motta se referiu ao Lulismo como momento de inovação-conservação (Motta, 2018), pode haver hoje um coletivismo-individualista em ação. Por mais ambíguo que pareçam tais afirmações, com elas alinhamo-nos à teoria de Georg Simmel, que entende elementos aparentemente antagônicos como formadores dos fenômenos sociais. É que o repertório clássico de conceitos de Simmel gira em torno das noções de aproximação e distância, à exemplo das interações sociais nas cidades (Simmel In Waizbort, 2000).

Com efeito, nessa virada de século, vê-se uma expansão do colaborativismo nas iniciativas criativas em geral, como aponta Maria Isabel de Almeida (Almeida \& Pais, 2012) a partir de entrevistas com cientistas e artistas. Essa aparente ambiguidade se resolve no fato de que o sistema ocidental tornou-se ele mesmo, a seu modo, colaborativo, e para servir a seus próprios interesses. Múltiplo, comunitário, feito a muitas mãos, a economia capitalista se utiliza dessas novas autorias colaborativas para se reinventar. No entanto laços colaborativos podem ser utilizados como sociação ou como dissociação, podem unir ou separar. Afinal, foram necessárias muitas alianças para chegarmos à alta modernidade e sua hiperaceleração que nos parece cada vez mais inviável para a saúde do mundo. Resta agora saber para que lado andarão esses laços, se serão construtivos ou destrutivos.

De volta ao mundo da arte, no período que se segue à Guerra Fria, parece mesmo ter-se assumido um compromisso com a valorização da coletividade. O papel do criador e do público, assim como os demais papeis na sociedade, se diluíram e se tornaram híbridos e flexíveis. Isso se acentua em tempos de digitalização. Com a desmaterialização da obra de arte, são possíveis novas formas de autoria que assumam esses novos papeis. Se a autoria coletiva remete ao sujeito em interação e dependência com o outro, isso significa que a alteridade ronda o próprio conceito de autoria. E como está nossa inter-relação com o outro atualmente? De que maneiras o museu reproduz essas relações?

Pode-se pensar que, como a participação do público é uma premissa modernista desde a década de 1960, a transformação do participante em coautor talvez tenha se dado de forma 'natural', apenas seguindo seu curso 
histórico. Mas, como colocado em Collectivism after modernism (Stimson \& Sholette, 2007), houve uma apropriação e uma ressignificação da relação entre o sujeito e o outro baseada principalmente na efemeridade da vida cotidiana: quando a autoria se abre ao não-planejado, ela se dissolve e a performance é co-criada pelo espectador, que está no aqui e no agora dela. Ele a atualiza.

Tomo agora como exemplo grandes exibições de arte contemporânea no mundo, a Documenta de Kassel e a Bienal de São Paulo, para refletir sobre como essas instituições vieram coletivizando seu discurso a partir de 1989. Pouco tempo depois da queda do muro de Berlim, na Documenta de Kassel de 1992, o curador Hoet descreveu sua missão curatorial com as seguintes palavras:

Em uma época em que a raça humana é confrontada mais do que nunca com perigos como a AIDS e as guerras multinacionais, catástrofes nucleares e desastres climáticos globais, em um momento em que as ameaças estão cada vez mais abstratas e os medos cada vez mais difusos, eu vejo a reflexão sobre as condições físicas da vida como uma resposta apropriada ${ }^{73}$.

E a descrição do Website segue da seguinte maneira:

\begin{abstract}
Hoet queria encontrar essa resposta não apenas em cooperação com sua proeminente equipe de curadores, composta por Bart de Baere, Pier Luigi Tazzi e Denys Zacharopoulos, mas também - e isso era uma novidade - através de uma estreita colaboração com os artistas. A discussão dentro do contexto deste esforço cooperativo não hierárquico girou acima de tudo em torno da posição das respectivas obras de arte e do diálogo resultante entre configurações e obras. Como Barbara Heinrich escreveu a esse respeito, 'Os artistas estiveram envolvidos no processo de criação da exposição desde o início'. Outra consequência inédita desta documenta foi a crítica de seu 'eurocentrismo' ocidental. Até então, no final do século $X X$, segmentos significativos da população tinham finalmente se conscientizado de que uma arte muito interessante estava sendo produzida na Ásia e no Terceiro Mundo também ${ }^{74}$.
\end{abstract}

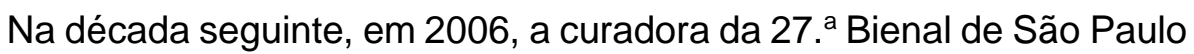
(“Como viver junto") destaca:

A $27^{a}$ Bienal de São Paulo propõe uma abordagem inovadora dentro da tradição da Fundação Bienal, excluindo as chamadas representações nacionais, sem colocar-se sob a legislação da grande máquina geopolítica que rege as decisões dos gabinetes culturais. É uma tendência visível nas últimas edições, que combinavam as indicações dos países com convidados do curador. Mesmo assim, permanecia uma espécie de hierarquia entre o 'artista oficial' e o 'artista convidado'. A $27^{\text {a }}$. Bienal olha para cada

\footnotetext{
73 Trecho retirado do site oficial da mostra. Disponível em: https://www.documenta.de/en/retrospective/documenta ix. Acesso em 10 de feveireiro de 2019.

Trecho retirado do site oficial da mostra. Disponível em:

https://www.documenta.de/en/retrospective/documenta ix. Acesso em 10 de feveireiro de 2019.
} 
participação como uma peça fundamental dentro de um projeto coeso, intitulado 'como viver junto'. Com esta mudança, a Bienal ganha autonomia e afirma sua independência institucional, cultural e politicamente. Trata-se de um 'evento propositor'. Na expressão de Mario Pedrosa, "O Brasil é um país condenado ao moderno". Moderno nesta visada, significa a reinvenção permanente. Para esta tarefa convidei curadores brasileiros e estrangeiros que partilharam comigo cada etapa, desde a afinação conceitual do meu anteprojeto até a discussão da planta museográfica. A assinatura é coletiva e provém de um comitê curatorial: Cristina Freire, Rosa Martínez, José Roca, Adriano pedrosa e eu. Ainda convidei Jochen Volz para curar o bloco Marcel Broodthaers ${ }^{75}$.

E então na próxima década, em 2018, na 33. ${ }^{a}$ Bienal de São Paulo intitulada Afinidades Afetivas, ainda acompanhamos essa tendência do coletivismo como forma de mostrar uma característica diferenciadora da mostra em relação às edições anteriores:

\begin{abstract}
Sendo assim, convidei sete artistas para compor a equipe curatorial, e para organizar uma exposição independente dentro do pavilhão, na qual suas próprias obras estivessem incluídas, ao lado dos artistas de sua escolha. Com este modelo, espero mostrar como os artistas constroem suas genealogias e sistemas para entender suas próprias práticas em relação aos outros, permitindo ao mesmo tempo que os temas e as relações surjam organicamente do processo da feitura da exposição, em vez de partir de um conjunto pré-determinado de questões. Essa escolha também reflete um desejo de reavaliar a tradição dos artistas como curadores, que é uma parte central da história da arte moderna e contemporânea e também particularmente relevante no Brasil, onde os artistas há muito tempo organizam suas próprias plataformas discursivas ${ }^{76}$.
\end{abstract}

Uma mostra por década, em 1990, 2000 e 2010. Vê-se nas descrições anteriores como estas utilizam as expressões derivadas do termo inovar para fazer da colaboração fonte de valor diferencial de cada evento. O mesmo ocorreu nas bienais de São Paulo dos últimos anos, onde um monitor então afirmava: "Esta á a primeira Bienal que conta com sete curadores, é uma curadoria coletiva" (como pude escutar na monitoria de 2014). Na de 2018, ouvia-se: "Esta é a primeira Bienal que conta com artistas curadores em uma curadoria coletiva". Assim, a premissa colaborativa e coletivista enquanto instrumento de inovação aparece como chave (ou como protagonista) para a compreensão de uma tendência importante da arte contemporânea.

Vê-se que, pelo menos desde 2006, a curadoria da Bienal de São Paulo, ainda que assinada por apenas um curador, descreve a si mesma como se expandindo em direção à curadoria coletiva. Vale destacar também

\footnotetext{
75 Trecho retirado do catálogo da mostra. Disponível em: http://www.bienal.org.br/publicacoes/2089. Acesso em 10 de fevereiro de 2019.

${ }^{76}$ Trecho retirado do site oficial da mostra. Disponível em http://33.bienal.org.br/pt/sobre-a-exposicao Acesso em 10 de fevereiro de 2018.
} 
a ênfase a não só um aspecto da autoria colaborativa, mas a diversos: colaborações entre artistas, entre artistas e público, ou ainda entre instituição, curadoria e público. Refirmam-se assim os papéis sociais 'hibridizados' no mundo da arte, em consonância com o hibridismo encontrado nas outras esferas da vida social, como apontam Shapiro e Heinich (2013) ao falarem das relações de família e de trabalho cada vez mais híbridas e flexibilizadas,

Ainda é preciso destacar que, dadas as contingências sócio-políticas que sublinham as classificações das artes, em tempos de crise iminente fazse ainda mais necessário refletir sobre as nuances do jogo classificatório entre estabelecidos e outsiders que os coletivos vêm promovendo desde sua consagração, e que estende-se agora para a discussão sobre a coletivização da autoria e colaboração nas instituições de arte - processo este cuja ambiguidade, aliás, é muito bem refletida pela crítica do jornal Valor Econômico sobre a 33. ${ }^{a}$ Bienal de São Paulo.

A proposta do curador-geral, o espanhol Gabriel Pérez-Barreiro, de delegar poder a sete artistas-curadores, pode ser tanto um processo democrático quanto um aceno ao neoliberalismo de terceirização de serviços. A opção não deixa de ser uma novidade aqui, ainda que possa reafirmar estereótipos elitistas. Depende do olhar ${ }^{77}$.

Para concluir: este estudo buscou enfatizar um hibridismo social recorrente na contaminação coletivista contemporânea, destacando o seguinte movimento discursivo: a arte indo para rua, e a rua indo para a instituição arte - mesmo sabendo que a rua tem diversos significados e que, na prática, só alguns de fato adentram os museus. Destacou-se também diversos subaspectos desses movimentos: a política invade a arte e a arte política invade o museu; os papéis do artista e do público têm as fronteiras turvadas; a autoria individual do artista se dilui e a colaboração com outros agentes se protagoniza; enquanto os coletivos se institucionalizam, as instituições se coletivizam. Termino com a esperança de que essas análises tenham podido oferecer, ao menos, um caminho por onde continuar as investigações deste tema da sociologia da arte.

\section{Referências Bibliográficas}

Almeida, M. \& Pais, J. (2012). Criatividade contemporânea e os redesenhos das relações entre autor e obra: a exaustão do rompante criador. In Almeida, M. \& Pais, J. (Orgs.) (2012). Criatividade juventude e novos horizontes profissionais.. Rio de Janeiro: Jorge Zahar.

\footnotetext{
${ }^{77}$ Disponível em: https://www.valor.com.br/cultura/5985221/politica-de-uma-bienal-sem-politica. Acesso em 10 de fevereiro de 2019.
} 
Arantes, O. (2014). Formas urbanas em mutação. Revista Eptic Online, Vol.16, n.1, pp. 58-67 (Entrevista realizada em outubro de 2013).

Assman, A. (2016). Espaços da recordação - Formas e transformações da memória cultural. Campinas: Ed. Unicamp.

Bishop, C. (2012). Artificial hells: participatory art and the politics of spectatorship. London: Verso.

Chagas, M. (2005). Museus: antropofagia da memória e do patrimônio. Revista do patrimônio histórico e artístico nacional, n. 31, pp. 10-35.

Chagas, M. (2003). Imaginação Museal: Museu, memória e poder em Gustavo Barroso, Gilberto Freyre e Darcy Ribeiro. Rio de Janeiro: Programa de Pós-Graduação em Ciências Sociais da Universidade do Estado do Rio de Janeiro.

Fernandes, T. (2018). Atrocidades maravilhosas, Zona Franca e a Escola de Belas Artes como propulsora de encontros e coletividade. Nuvem arte e crítica. Disponível em: https://nuvemcritica.wordpress.com/2018/07/09/atrocidades-maravilhosas-zonafranca-e-a-escola-de-belas-artes-como-propulsora-de-encontros-e-coletividade/ Acesso em 10 de fevereiro de 2019.

Fialho, A. L. (2017). O mercado, os artistas, os colecionadores e as instituições. OuvirOUver, 13(2), pp. 378 - 390.

GUERRA, P. (2014). Punk, expectations, breaches and metamorphoses: Portugal, 19772012. Critical Arts, Vol. 28, n. ${ }^{\circ}$, pp. 111-122.

Harvey, D. (2013). A liberdade da cidade. In Maricato, E., Cidades Rebeldes: Passe livre e manifestações que tomaram as ruas do Brasil. São Paulo: Boitempo.

Madeira, A. (2016). Arte compartilhada: uma teoria possível. In Quemin, A. \& Villas Bôas, G. (Orgs) Arte e Vida Social. Marseille: OpenEdition Press.

Miranda, Ana (2016). Coletivos de arte: a artificação da criação coletiva nos anos 2000. Revista NAVA, v. 1, n. 2, janeiro-junho.

Motta, G. (2018). Discursos de contrainformação: coletivos de artistas e curadoresautores no Brasil (2000-2015). Tese de Doutorado do Programa de Pós-Graduação em Artes Visuais da Universidade de São Paulo.

Mussi, J. Z. (2014). O Espaço como obra: ações, coletivos artísticos e cidade. São Paulo: Annablume Editora, FAPESP, Invisíveis Produções.

Pires, E. (2007). Cidade ocupada. Rio de Janeiro: Aeroplano.

Rezende, R. \& Scovino, F. (2010). Coletivos. Rio de Janeiro: Editora Circuito.

Sant'anna, S., Marcondes, G. \& Miranda, A. (2017). Arte e política: a consolidação da arte como agente na esfera pública. Sociol. Antropol. / Rio de Janeiro, v.07.03, pp. 825849.

Sant'anna, S. (2012). Memória e modernidade: notas para refletir sobre memória e 
museus de um ponto de vista sociológico. Panóptica, Vitória, vol. 7, n. 2 (n. 24).

Stimson, B. \& Sholette, G. (2007). Collectivism after modernism: The Art of Social Imagination after 1945. Minneapolis: University of Minnesota Press.

Shapiro, R. \& Heinich, N. (2013). Quando há artificação?. Sociedade e Estado, 28(1), pp. 14-28.

Waizbort, L. (2000). As aventuras de Georg Simmel. São Paulo: Editora 34. 